\title{
Exploring the Possibilities for Quality Improvement: An Internal Customer Perspective
}

Ines Dužević

Faculty of Economics and Business - Zagreb

Email: iduzevic@efzg.hr

Tomislav Baković

Faculty of Economics and Business - Zagreb

Email: tbakovic@efzg.hr

Doi:10.5901/mjss.2014.v5n13p29

\author{
Ivana Štulec \\ Faculty of Economics and Business - Zagreb \\ Email: istulec@efzg.hr
}

\begin{abstract}
Surveys of service quality are usually based on the analysis of external customers' expectations and perceptions, neglecting the attitudes and expectations of internal customers. However, internal customers have a very important role in the service quality system, especially in the service industry. In higher education, the role of internal customers is particularly important. Service quality in higher education depends mainly on the competences and performance of the faculty. Accordingly, the main goal of this study is to explore internal customers' perceptions of service quality in higher education and to define possible quality improvements. Higher education service quality is analysed using a modified SERVQUAL instrument, adjusted for the higher education context. Exploratory factor analysis is used to define key service quality dimensions. Furthermore, the results are compared based on personal and institutional characteristics. In addition, this study includes an analysis of faculty satisfaction with the working environment and working conditions at higher education institutions. The results provide useful information for the management of higher education institutions, which can be used in the design and customization of quality plans aimed at fulfilling the needs and expectations of their internal customers.
\end{abstract}

Keywords: service quality, internal customer, customer satisfaction, higher education, Croatia

\section{Introduction}

Service quality is usually related to customer satisfaction. The most important customers of an organization are its external customers or consumers. However, the role of internal customers is equally important, especially in the service industry. Internal customers, or employees, may have significant impact on the service provisioning results and external customers' satisfaction.

The human interrelationships that shape customers' expectations and perceptions dominantly affect quality (Behra \& Gundersen, 2001). More engaged faculty and students are important determinants of education quality (Newswier \& Borrego, 2009). Faculty engagement and commitment create a culture and an environment that encourage student involvement. Faculty who challenge their students to solve more complex problems and who collaborate with students on their projects create an environment that encourages student involvement and, consequently, improve student learning outcomes. The behaviour of the faculty shapes students' approach to learning, which then affects students' outcomes (Nelson Laird et al., 2008). The faculty's service quality perceptions and job satisfaction influence students' satisfaction and results. Therefore, it is important to measure and strive to improve internal customer satisfaction.

The aim of this paper is to explore how faculty perceive service quality and to examine the level of their satisfaction with their job and working environment. The findings of the study provide valuable insight into quality improvement initiatives for HEl management. 


\section{Literature Review}

In the higher education system, the role and responsibility of faculty is very important. Their behaviour and attitudes affect the HEl results (Ryan et al., 2011), and their approach to teaching affects students' approach to learning (Trigwell et al., 1999). Job satisfaction drives faculty's effectiveness and attitudes. Satisfied faculty are more involved in teaching and extracurricular activities, creating a favourable environment for the development of positive faculty-student interactions. Moreover, faculty satisfaction is related to students' engagement, results, cooperativeness, promotion, and research publication (Rosser, 2004). Therefore, faculty satisfaction is a significant determinant of HEl service quality and students' learning outcomes.

Faculty satisfaction consists of the level of their satisfaction with students, colleagues, and management (Rosser, 2004). Among faculty, a high level of satisfaction with their students is related to their overall job satisfaction. Other determinants of faculty satisfaction include earnings, working conditions and regulations, and job security. Ryan et al. (2011) showed that the most significant determinants of faculty job satisfaction are the job itself, earnings, relations with management, quality of and relations with students, and institutional culture and climate. Chen et al. (2006) developed an employee satisfaction model for higher education that includes the following concepts: HEI vision, respect, motivation and feedback, management system, earnings and benefits system, and working environment. They found that employees in higher education are focused on high earnings and a fair promotion system. Snipes et al. (2005) concluded that job satisfaction includes satisfaction with management, job, earnings, promotion opportunities, colleagues, and customers.

Rosser (2004) stated that the perceived quality of the working environment has a significant influence on faculty satisfaction and consists of individual characteristics, job-related issues, and satisfaction. These constructs affect faculty behaviour and their decision to leave or keep the job. Chang et al. (2010) examined whether the support provided to the faculty influenced their effectiveness. In their study, support for the faculty consisted of teaching resources, administrative support, and expert support. Effectiveness was measured using a course design, strategies for teaching, technology in teaching, class organization, interpersonal relationships, and an examination system. The authors confirmed a positive but weak relationship between perceived faculty support and teaching effectiveness.

Evidently, faculty satisfaction has a very significant influence on HEI service quality and students' results. Previous studies showed a positive effect of faculty satisfaction on faculty effectiveness and behaviour (Rosser, 2004). These attitudes and behaviours shape the organizational culture at the HEl. The faculty culture, including their roles and expectations, affects students' learning and engagement (Umbach \& Wawrzynski, 2005). This culture moderates students' perceptions of their outcomes, knowledge, and practical skills. According to some studies, faculty have the most significant influence on students' study experience (Umbach \& Porter, 2002).

Snipes et al. (2005) conducted research on 351 employees and 8667 customers of higher education to determine the specific aspects of job satisfaction with the most significant impact on perceived service quality. Their results showed that managerial efforts related to internal customer job satisfaction, such as perceptions about the job, may have the most significant influence on service quality compared with other satisfaction aspects. Earnings, potential awards, and operations have lesser influence on service performance compared with internal aspects of faculty satisfaction. Thus, the results indicate that faculty who are more satisfied with their customers provide a higher level of service quality. From the management perspective, to improve service quality employment, the selection of candidates should focus on those who are more customer-oriented.

Trivellas and Dargenidou (2009) pointed out that faculty satisfaction leads to higher quality in tangible aspects. Moreover, faculty satisfaction positively affects two quality dimensions: academic and access. These two dimensions include the attitudes, behaviour, and competencies of the faculty and are closely related to their satisfaction. Furthermore, faculty satisfaction moderates the behaviour and effectiveness of faculty and consequently influences students' results (Rosser, 2004). Faculty behaviour can influence the following students' results: intrinsic motivation (Chang et al., 2010), active and collaborative learning (Wolf-Wendel et al., 2009), engagement and results (Chang et al., 2010; Kember, 2009; Umbach \& Wawrzynski, 2005), and students' satisfaction (Trivellas \& Dargenidou, 2009). Faculty satisfaction moderates the attitudes and behaviours that significantly shape students' behaviours and engagement and simultaneously affect the quality of the higher education service.

\section{Research Method}

\subsection{Survey instrument}

Service quality is usually measured with the SERVQUAL (service quality) instrument. This instrument measures a 
customer's expectations and perceptions by using 22 items for each variable (Parasuraman et al., 1985). The analysis of the SERVQUAL results divides service quality into five dimensions: tangibles, reliability, assurance, responsiveness, and empathy. Critics of this approach argue that it is not necessary to measure expectations because these are already included in customer's perceptions (Grönroos, 2001). Thus, based on the perception-only approach, the SERVPERF (service performance) instrument was developed. This instrument is a modification of SERVQUAL and includes only 22 items related to customer's perceptions. Some researchers have shown that SERVPERF is a better instrument for measuring service quality (Cronin \& Taylor, 1992; Firdaus, 2006b), whereas others have demonstrated that both instruments are valuable and useful (Bayraktaroglu \& Atrek, 2010; Brandon-Jones \& Silvestro, 2010; Brocado, 2009).

Based on the service performance paradigm, Firdaus (2006a) developed an instrument for measuring service quality in the higher education context, which is called HEdPERF (higher education performance). This instrument consists of 41 items that measure five service quality dimensions: nonacademic, academic, reputation, access, and study programmes. Because HEdPERF has proven to be reliable instrument for measuring higher education service quality, it was used for the purpose of this study. The instrument items are presented in Appendix 1. Along with the questions in the HEdPERF instrument questions, the research questionnaire included items related to satisfaction with job and with working environment. These items were modified according to Snipes et al. (2005).

\subsection{Sample}

The survey was conducted by using an online questionnaire administered in all HEls in Croatia from May to October 2012. In total, 821 academic staff from 93 HEls answered the questionnaire. At that time, there were $133 \mathrm{HEls}$ in Croatia. Thus, most of the HEls in the country were included in the research. Of the 821 respondents, $44 \%$ were males and $56 \%$ were females. Almost all of the respondents (95\%) were full-time employees at the HEls and came from public HEls (90\%). Regarding work, the respondents were from the fields of social science (31\%), technical science (24\%), humanities (13\%), biomedicine and health (9\%), biotechnology (9\%), natural science (9\%), interdisciplinary studies (3\%), and arts (2\%).

\subsection{Methods}

Principal component analysis (PCA) on the HEdPERF items was done with PASW Statistics 18. A Likert scale with values ranging from 1 to 7 was used, with 1 representing complete disagreement with the statement and 7 indicating complete agreement with the statement. Principal component analysis was used to define key service quality dimensions in Croatian higher education based on faculty perception. Prior to implementing the PCA, we checked the suitability of the collected data for factor analysis. After inspecting the correlation matrix, we found the existence of a large number of correlation coefficients equal to or more than 0.3 . The Kaiser-Meyer-Olkin criteria, with a value of 0.963 , and Bartlett's test, which was shown to have a statistical significance of $1 \%$, supported the suitability for factor analysis of the data collected through the survey.

The second part of the analysis included structural equation modelling based on the partial least squares (PLS) algorithm. All estimations in this study were conducted with the SmartPLS 2.0 software (Ringle et al., 2005). Estimations were conducted on mean-centred data by using the path weighting scheme. Pre-modelling activities included a thorough explorative data analysis. PASW Statistics 18 was used to check the normality of the data and to calculate other descriptive statistics. This analysis enabled an examination of the relations between perceived service quality dimensions and faculty satisfaction with job and with working environment.

\section{Analysis and Results}

Principal component analysis revealed the existence of five components. The solution with five factors explained $60.95 \%$ of the total variance in faculty perception of service quality. To interpret the solution with five factors, an oblique rotation of factors was implemented, given that the correlation matrix of the components showed a correlation with individual absolute values of 0.3 or above. The factors selected in the analysis were: academic, which included the accountability of academic staff at HEls; nonacademic, which included items related to the accountability of nonacademic staff at HEls; facilities of the HEl; access, which included counselling services and service approachability and reliability; and reputation of the HEl. 
Table 1. Results of the PCA analysis - Service quality dimensions

\begin{tabular}{|l|c|c|c|c|c|}
\hline & \multicolumn{5}{|c|}{ Service quality dimensions } \\
\cline { 2 - 6 } & Academic & Nonacademic & Facilities & Access & Reputation \\
\hline \multicolumn{1}{|c|}{ Explained variance } & 42.96 & 7.02 & 2.94 & 3.19 & 4.84 \\
\hline Mean (standard deviation) & $5.56(0.94)$ & $5.31(1.19)$ & $4.39(1.15)$ & $5.36(1.06)$ & $4.92(1.07)$ \\
\hline No. of items per factor & 12 & 10 & 4 & 5 & 10 \\
\hline Cronbach's alpha & 0.84 & 0.85 & 0.90 & 0.82 & 0.82 \\
\hline
\end{tabular}

As shown in Table 1, all service quality dimensions have a Cronbach's alpha value above 0.7 . The alpha values were also calculated for satisfaction dimensions. For faculty job satisfaction, the alpha value was 0.89 ; for faculty satisfaction with work environment, it was 0.79 . Faculty perceived the academic dimension to be the most satisfying attribute of service quality, followed by access and the nonacademic dimension. HEI facilities and reputation were the worstperforming dimensions. The factor structure is slightly different from that in the original research conducted by Firdaus (2006a). According to the results shown in Appendix 1, faculty connected many items related to the study programmes with the HEI reputation, whereas facilities were separated from reputation. Moreover, some items that were included in the access dimension in the Firdaus research were included in the academic dimension.

Table 2. Results of the PLS analysis - model fit

\begin{tabular}{|l|c|c|c|c|c|}
\hline & AVE & Composite Reliability & R Square & Communality & Redundancy \\
\hline Academic & 0.59 & 0.94 & 0.00 & 0.59 & 0.00 \\
\hline Access & 0.63 & 0.89 & 0.00 & 0.63 & 0.00 \\
\hline Facilities & 0.47 & 0.77 & 0.00 & 0.47 & 0.00 \\
\hline Nonacademic & 0.67 & 0.95 & 0.00 & 0.67 & 0.00 \\
\hline Reputation & 0.51 & 0.91 & 0.00 & 0.51 & 0.00 \\
\hline Job satisfaction & 0.76 & 0.93 & 0.65 & 0.76 & 0.03 \\
\hline Working environment satisfaction & 0.50 & 0.85 & 0.44 & 0.50 & 0.04 \\
\hline
\end{tabular}

We then assessed the reflective measurement model (Table 2). The composite reliability (CR) scores for the reflectively identified exogenous and endogenous constructs indicated high internal consistency. The average variances extracted (AVE) were close to or exceeded the cutoff value of 0.5 , thus indicating sufficient convergent validity. Furthermore, the constructs met the Fornell-Larcker criterion of discriminant validity (Henseler et al., 2009). An examination of the absolute standardized outer loadings further revealed a sufficient level of indicator reliability. Although not all the loadings exceeded the cutoff value of 0.7 , scores above 0.5 can be considered acceptable when the respective constructs are measured by other indicators as well (e.g., Chin, 1998).

Table 3. Results of the PLS analysis - path coefficients and significance testing

\begin{tabular}{|l|c|c|c|c|c|c|}
\hline & Original Sample Sample Mean & Standard Deviation & Standard Error T Statistics & Significance \\
\hline Academic -> job satisfaction & 0.03 & 0.04 & 0.04 & 0.04 & 0.89 & 0.37 \\
\hline Academic -> w.e. satisfaction & 0.08 & 0.08 & 0.04 & 0.04 & 1.91 & $\mathbf{0 . 0 5}$ \\
\hline Access -> job satisfaction & 0.11 & 0.11 & 0.04 & 0.04 & 2.56 & $\mathbf{0 . 0 1}$ \\
\hline Access -> w.e. satisfaction & 0.29 & 0.29 & 0.04 & 0.04 & 6.64 & $\mathbf{0 . 0 0}$ \\
\hline Facilities -> job satisfaction & 0.00 & 0.00 & 0.02 & 0.02 & 0.03 & 0.98 \\
\hline Facilities -> w.e. satisfaction & 0.09 & 0.09 & 0.03 & 0.03 & 3.43 & $\mathbf{0 . 0 0}$ \\
\hline Nonacademic -> job satisfaction & 0.07 & 0.07 & 0.03 & 0.03 & 1.93 & $\mathbf{0 . 0 5}$ \\
\hline Nonacademic -> w.e. satisfaction & 0.12 & 0.12 & 0.04 & 0.04 & 3.18 & $\mathbf{0 . 0 0}$ \\
\hline Reputation -> job satisfaction & 0.23 & 0.22 & 0.04 & 0.04 & 5.67 & $\mathbf{0 . 0 0}$ \\
\hline Reputation -> w.e. satisfaction & 0.18 & 0.19 & 0.05 & 0.05 & 3.82 & $\mathbf{0 . 0 0}$ \\
\hline w.e. satisfaction -> job satisfaction & 0.49 & 0.49 & 0.03 & 0.03 & 16.46 & $\mathbf{0 . 0 0}$ \\
\hline
\end{tabular}

Figure 1 shows the path model and relationships in the proposed model, and Table 3 provides information about the significance of the proposed relationships between focal variables. The results indicated statistical significance for most of the proposed relationships. All four service quality dimensions were shown to affect faculty satisfaction with the work 
environment. The strongest influence existed between working environment satisfaction and access, reputation, and nonacademic dimension, whereas the relationship between other service quality dimensions and working environment satisfaction was weak. Overall job satisfaction was positively related to HEI reputation, access, and nonacademic dimension. Job satisfaction had no significant correlation with facilities and academic dimension. However, these influences may be indirect, moderated by faculty satisfaction with the working environment. Among the service quality dimensions, the most important determinant of job satisfaction was institutional reputation, followed by access and the nonacademic dimension. Overall job satisfaction was driven mostly by satisfaction with the work environment.

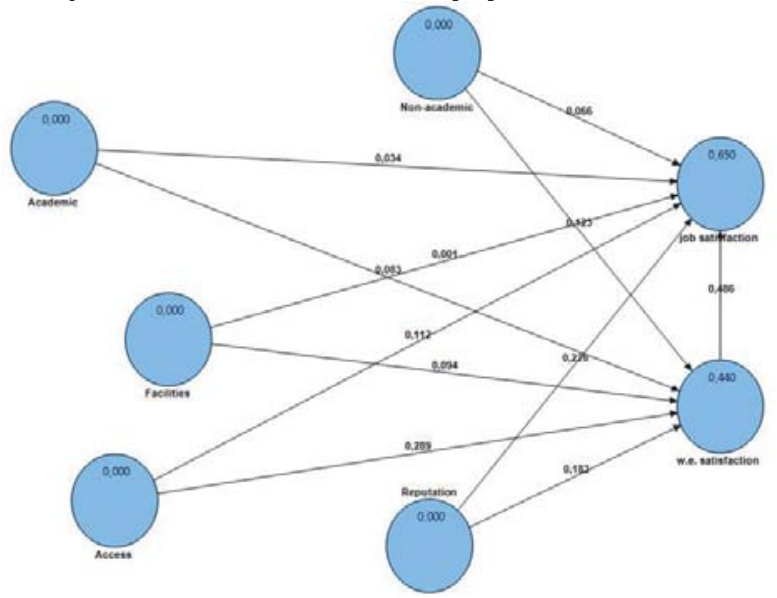

Figure 1. Relationships between service quality and faculty satisfaction - path diagram

There are several limitations to this study. First, the results of the study refer to the Croatian higher education system and cannot be generalized to other populations. Moreover, the study is based on the subjective assessment and perceptions of faculty, which may have an impact on the results. For example, faculty might have assessed the academic dimension with the highest ratings because it is related to their responsibilities, performance, and competencies. Third, this study includes an assessment from only one customer group in the higher education system. More relevant conclusions can be drawn if assessments from other customer groups (e.g., students, graduates, administrative staff, and employer representatives) are included.

\section{Conclusion}

Internal customers are a very important link in the service quality chain. In the higher education system, the role of internal customers is especially important. Their behaviour and approach to work may affect students' results and satisfaction. Moreover, their research activities and scientific achievements increase the HEl reputation. Satisfied faculty are a source of competitive advantage because only satisfied employers can achieve excellent results. Therefore, it is extremely important to evaluate faculty satisfaction and perceptions about higher education service quality.

In this study, faculty assessed the academic, access, and nonacademic dimensions as the most satisfying, whereas facilities and reputation received the lowest ratings. However, faculty related some access items with the academic and nonacademic dimensions, and study programme items were included in the reputation dimension. Another surprising result was faculty's assessment of facilities and reputation. The HEI infrastructure and facilities depend on institutional strategy and budgetary constraints, and faculty cannot initiate changes in this service attribute. However, faculty have a significant amount of freedom in creating and reviewing study programmes. Keeping this in mind, the management of Croatian HEl must encourage faculty to regularly monitor and update their courses.

To enhance service quality, managers in the Croatian HE system should focus on improving facilities and building up institutional reputation. Given the decreasing government funding due to the poor economic situation of the country, HEls can seek other funding sources through cooperation with industries and business communities. This cooperation may have a positive effect, not only in obtaining investment in facilities but also in enhancing the HEI reputation and faculty satisfaction. Moreover, increased marketing activities are needed at Croatian HEIs in order to emphasise the good practices that are being implemented.

All service quality dimensions have significant positive impact on faculty satisfaction. The key drivers of faculty 
satisfaction are institutional reputation and access, and satisfaction with working environment. A stimulating working environment has a higher influence on overall faculty satisfaction. Accordingly, the HEI management needs to ensure good working conditions and encourage collaboration and teamwork. The implementation of proposed service quality initiatives may help the management of Croatian HEls to achieve their quality management goals and improve their performance. Furthermore, enhanced faculty satisfaction will positively influence their reputation (which was one of the lowest-performing service quality dimensions). To conclude, by focusing on the satisfaction of internal customers, institutions may achieve their service quality goals and improve their reputation and performance.

\section{References}

Bayraktaroglu, G., Atrek, B. (2010). Testing the Superiority and Dimensionality of SERVQUAL vs. SERVPERF in Higher Education. The Quality Management Journal, 17(1), 47-59.

Behra, R.S., Gundersen, D.E. (2001). Analysis of quality management practices in services. International Journal of Quality and Reliability Management, 18(6), 584-603.

Brandon-Jones, A., Silvestro R. (2010). Measuring internal service quality: comparing the gap-based and perception-only approaches. International Journal of Operations and Production Management, 30(12), 1291-1318.

Brocado, A. (2009). Comparing alternative instruments to measure service quality in higher education. Quality Assurance in Education, $17(2), 174-190$.

Chang, T.S., McKeachie, W., Lin, Y.G. (2010). Faculty perception of teaching support and teaching efficacy in Taiwan. Higher Education, $59,207-220$.

Chen, S.H., Yang, C.C., Shiau, J.Y. (2006). The application of balanced scorecard in the performance evaluation of higher education. The TQM Magazine, 18(2), 190-205.

Chin, W.W. (1998). The partial least squares approach to structural equation modelling, in Marcoulides, G. A. (Ed.). Modern methods for business research, Lawrence Erlbaum Associates, Mahwah, NJ, 295-336.

Cronin Jr, J.J., Taylor, S.A. (1992). Measuring Service Quality: A Reexamination and Extensions. Journal of Marketing, 56, 55-68.

Firdaus, A. (2006a). The development of HEdPERF: a new measuring instrument of service quality for the higher education sector. International Journal of Consumer Studies, 30(6), 569-581.

Firdaus, A. (2006b). Measuring service quality in higher education: HEdPERF versus SERVPERF. Marketing Intelligence \& Planning, 24(1), 31-47.

Grönroos, C. (2001). The perceived service quality concept - a mistake? Managing Service Quality, 11(3), 150-152.

Henseler, J., Ringle, C.M., Sinkovics, R.R. (2009). The use of partial least squares path modeling in international marketing, in Sinkovics, R.R. and Ghauri, P.N. (Eds.). Advances in international marketing. 20, Emerald Group Publishing Limited, Bingley, 277-319.

Kember, D. (2009). Promoting student-centred forms of learning across an entire university, Higher Education. 58, 1-13.

Nelson Laird, T.F., Shoup, R., Kuh, G.D., Schwartz, M.J. (2008). The Effects of Discipline on Deep Approaches to Student Learning and College Outcomes. Research in Higher Education, 49, 469-494.

Newswier, L.K., Borrego, M. (2009). Engagement in two interdisciplinary graduate programs. Higher Education, 58, 551-562.

Parasuraman, A., Zeithaml, V.A., Berry, L.L. (1985). A Conceptual Model of Service Quality and Its Implications for Future Research. The Journal of Marketing, 49(4), 41-50.

Parasuraman, A., Zeithaml, V.A., Berry, L.L. (1988). SERVQUAL: A Multiple-Item Scale for Measuring Consumer Perceptions of Service Quality. Journal of Retailing, 64(1), $12-40$.

Ringle, C., Wende, S., Will, A. (2005). SmartPLS 2.0, Hamburg, available at: http://www.smartpls.de (accessed 15 March 2014).

Rosser, V.J. (2004). Faculty Members' Intention to Leave: A National Study of Their Worklife and Satisfaction. Research in Higher Education, 45(3), 285-309.

Ryan, J.F., Healy, R., Sullivan, J. (2011). Oh, won't you stay? Predictors of faculty intent to leave a public research university. Higher Education, doi: 10.1007/s10734-011-9448-5.

Snipes, R.L., Oswald, S.L., LaTour, M., Armenakis, A.A. (2005). The effect of specific job satisfaction facets on customer perceptions of service quality: an employee-level analysis. Journal of Business Research, 58, 1330-1339.

Sultani, P., Wong, H. (2010). Performance-based service quality model: an empirical study on Japanese universities. Quality Assurance in Education, 18(2), 126-143.

Trigwell, K., Prosser, M., Waterhouse, F. (1999). Relations Between Teachers' Approaches to Teaching and Students' Approaches to Learning. Higher Education, 37, 57-70.

Trivellas, P., Dargenidou, D. (2009). Leadership and service quality in higher education - The case of the Technological Educational Institute of Larissa. International Journal of Quality and Service Sciences, 1(3), 294-310.

Umbach, P.D., Porter, S.R. (2002). How do Academic Departments Impact Student Satisfaction? Understanding the Contextual Effects of Departments. Research in Higher Education, 43(2), 209-234.

Umbach, P.D., Wawrzynski, M.R. (2005). Faculty Do Matter: The Role of College Faculty in Student Learning and Engagement. Research in Higher Education, 46(2), 153-184.

Wolf-Wendel, L., Ward, K., Kinzie, J. (2009). A Tangled Web of Terms: The Overlap and Unique Contribution of Involvement, 
Engagement, and Integration to Understanding College Student Success. Journal of College Student Development, 50(4), 407428.

Appendix 1. Rotated Component Matrix - Service quality dimensions

\begin{tabular}{|c|c|c|c|c|c|}
\hline & \multicolumn{5}{|c|}{ Service quality dimension } \\
\hline & Nonacademic & Academic & Reputation & Access & $\begin{array}{c}\mathrm{HEI} \\
\text { facilities }\end{array}$ \\
\hline The administrative staff communicates well with students. & .840 & & & & \\
\hline The administrative staff shows a positive work attitude towards students. & .827 & & & & \\
\hline The administrative staff provides caring and individual attention. & .800 & & & & \\
\hline $\begin{array}{l}\text { When a student has a problem, the administrative staff shows a sincere } \\
\text { interest in solving it. }\end{array}$ & .779 & & & & \\
\hline Inquiries/complaints are dealt with efficiently and promptly. & .775 & & & & \\
\hline When the staff promise to do something by a certain time, they do so. & .766 & & & & \\
\hline The administrative staff has good knowledge of the systems/procedures. & .730 & & & & \\
\hline Administration offices keep accurate and retrievable records. & .712 & & & .335 & \\
\hline $\begin{array}{l}\text { The opening hours of administrative offices are convenient for students' } \\
\text { needs. }\end{array}$ & .696 & & & & \\
\hline $\begin{array}{l}\text { The administrative staff is never too busy to respond to a request for } \\
\text { assistance. }\end{array}$ & .467 & & & & .317 \\
\hline The academic staff shows a positive attitude towards students. & & .810 & & & \\
\hline The academic staff allocates sufficient and convenient time for consultation. & & .809 & & & \\
\hline $\begin{array}{l}\text { When a student has a problem, the academic staff shows a sincere interest in } \\
\text { solving it. }\end{array}$ & & .786 & & & \\
\hline The academic staff deals with students in a caring and courteous manner. & & .768 & & & \\
\hline The academic staff communicates well in the classroom. & & .752 & & & \\
\hline The academic staff provides feedback about students' progress. & & 697 & & & \\
\hline $\begin{array}{l}\text { The academic staff are highly educated and experienced in their respective } \\
\text { fields. }\end{array}$ & & .648 & & & \\
\hline $\begin{array}{l}\text { The academic staff has the knowledge to answer students' questions related } \\
\text { to course content. }\end{array}$ & & .616 & & & \\
\hline Students are treated equally and with respect by the staff. & .420 & .520 & .330 & .345 & \\
\hline The staff ensure that they are easily contacted by telephone. & .350 & .473 & & .465 & \\
\hline $\begin{array}{l}\text { The staff respects the student's confidentiality when (s)he discloses } \\
\text { information to them. }\end{array}$ & .329 & .443 & & .433 & \\
\hline Students are given a fair amount of freedom. & & .396 & & .386 & \\
\hline The institution offers highly reputable programmes. & & & .704 & & \\
\hline $\begin{array}{l}\text { The institution offers a wide range of programmes with various } \\
\text { specialisations. }\end{array}$ & & & .678 & & \\
\hline The institution offers programmes with a flexible syllabus and structure. & & & .669 & & \\
\hline The institution runs excellent-quality programmes. & & .304 & .615 & & \\
\hline Class sizes are kept to a minimum to allow personal attention to students. & & & .571 & & \\
\hline The institution's graduates are easily employable. & & & .509 & & \\
\hline Students feel secure and confident in their dealings with this institution. & .380 & .354 & .463 & .439 & \\
\hline $\begin{array}{l}\text { The institution has an ideal location with an excellent campus layout and } \\
\text { appearance. }\end{array}$ & & & .457 & & \\
\hline The institution operates excellent counselling services. & .320 & .346 & .439 & .385 & \\
\hline The institution has a professional appearance/image. & & .320 & .432 & .354 & \\
\hline The institution encourages and promotes the setting up of a students' union. & & & & 676 & \\
\hline Health services are adequate. & & & & .563 & \\
\hline The institution has a standardized and simple service delivery procedure. & .378 & .339 & .349 & .527 & \\
\hline $\begin{array}{l}\text { The institution values feedback from students towards improving its service } \\
\text { performance. }\end{array}$ & .379 & .384 & .322 & .497 & \\
\hline The institution provides services within a reasonable/expected time frame. & .376 & .326 & .450 & .460 & \\
\hline The hostel facilities and equipment are adequate. & & & & & .742 \\
\hline Academic facilities are adequate. & & & & & .709 \\
\hline Recreational facilities are adequate. & & & & & .519 \\
\hline $\begin{array}{l}\text { The academic staff is never too busy to respond to a student's request for } \\
\text { assistance. }\end{array}$ & & & & & .436 \\
\hline
\end{tabular}

Notes: Extraction Method: Principal Component Analysis.

Rotation Method: Varimax with Kaiser Normalization.

Rotation converged in 7 iterations. 